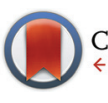

CrossMark \& click for updates

Cite this: Dalton Trans., 2016, 45 11035

Received 31st March 2016,

Accepted 9th June 2016

DOI: $10.1039 / c 6 d t 01234 \mathrm{e}$

www.rsc.org/dalton

\title{
Palladium 1D nanoscale aggregates on a graphite surface using CTAB hemicylindrical micelle templates $\uparrow$
}

\author{
I. R. Nizameev, ${ }^{a, b}$ M. K. Kadirov, ${ }^{* a, c}$ V. A. Semyonov, ${ }^{c}$ L. Ya. Zakharova, ${ }^{a}$ T. I. Ismaev, ${ }^{c}$ \\ R. A. Safiullin, ${ }^{c}$ I. Kh. Rizvanov ${ }^{a}$ and V. M. Babaev ${ }^{a}$
}

\begin{abstract}
Nanoscale palladium clusters in the form of parallel strips have been formed on the surface of graphite with the help of a surface micellar template of cetyltrimethylammonium bromide using a chemical deposition method. The repeat period of the palladium strips deposited at $25^{\circ} \mathrm{C}$ is $65 \mathrm{~nm}$, with a width of $40 \mathrm{~nm}$ and height of $2 \mathrm{~nm}$. The elemental composition of the metal clusters was confirmed using X-ray fluorescence analysis and TEM-EDX. The fact that the strips are composed of metallic palladium was also confirmed by testing the membrane electrode assembly with the strips in a commercial fuel cell. Using the obtained micellar template, the radius of the curvature of the AFM probe tip was estimated with the help of a unique method. The radius is equal to $10 \mathrm{~nm}$ and matches the value provided by the manufacturer.
\end{abstract}

\section{Introduction}

The properties of materials and the functional capabilities of macroscopic objects change significantly when one or more dimensions becomes less than $100 \mathrm{~nm} .{ }^{1}$ Nanoparticles/ quantum dots (null-dimensional or 0D), ${ }^{2,3}$ nanowires/nanotubes (one-dimensional or $1 \mathrm{D})^{4-6}$ or thin films (two-dimensional or $2 \mathrm{D})^{7}$ are the main forms of low-dimensional nanomaterials. 1D-nanomaterials are very attractive as their geometry and large surface area provide them with high functionality. For example, metal nanowires (MNWs) will, probably, become an integral part of future nanodevices. They can at least be used as elements, connecting circuit components. ${ }^{8}$

MNWs can also be used as memory elements with a high storage density, ${ }^{9}$ as highly sensitive nanoscale sensors, ${ }^{10}$ magnetoresistive multi-layer wires ${ }^{11}$ and so on. Ordered arrays of MNWs are of primary concern. Recently, ${ }^{12}$ experts in the R\&D department at Hewlett-Packard (HP) proved the existence of a memristor ${ }^{13}$ - the fourth passive element of electronics, using

\footnotetext{
${ }^{a}$ A.E. Arbuzov Institute of Organic and Physical Chemistry, Kazan Scientific Center, Russian Academy of Sciences, 8, Akad. Arbuzova str., Kazan 420088, Russia. E-mail: kadirovmarsil@gmail.com

${ }^{b}$ Kazan National Research Technical University, 10, K. Marx str., Kazan 420111, Russia

${ }^{c}$ Kazan National Research Technological University, 68, K. Marx str., Kazan 420015, Russia

$\dagger$ Electronic supplementary information (ESI) available: AFM images of palladium on HOPG surface, AFM images of the structure of CTAB at the graphitewater interface. See DOI: 10.1039/c6dt01234e
}

a system of platinum parallel strips. However, there is no efficient, low cost and quick commercial method to produce such structures.

At the present stage of science development, ordered arrays of metal clusters are mainly produced with the help of nanolithography. This method requires extreme precision and expensive probe technologies, which allow manipulation of certain metal nanoclusters. Besides the fact that such technologies require expensive equipment, they are in situ methods and it is necessary to spend a lot of money and effort to create a small system of several nanometers.

Recently, one-dimensional (1D) self-assemblies of Pt nanoparticles such as wires or structures with a necklace-like morphology on a graphite surface have been synthesized. A template-directed sintering process of individual nanoparticles, using non-ionic/cationic mixed hemi-cylindrical micelle templates of dodecyldimethylamine oxide surfactant at the graphite/solution interface, was used. ${ }^{14,15}$ We improved the method of platinum lattice production on the graphite surface. ${ }^{16}$ This method allows control of the morphological characteristics of the synthesized platinum nanolattice. These characteristics directly depend on the morphological characteristics of the original hemi- and pre-cylindrical micellar templates, which can be controlled with the temperature of deposition. AFM proved to be very informative and was widely used to study the morphology of both the micellar self-associated templates and Pt clusters. In addition, it seems very promising for developing nanolattices from parallel strips of noble metals using non-conducting clear surfaces. Electron 
spin resonance (ESR) proved to be another very productive method that can shed light on the process of self-organization of the surfactants on non-conductive surfaces. The wide modern capabilities of ESR are known through its applications in the direct registration of decomposition products in perfluorosulphonated membranes, ${ }^{17-19}$ investigation of micelles of classical surfactants in bulk solutions, ${ }^{20}$ amphiphilic calix [4] $\operatorname{arenes}^{21}$ and simultaneous studies of paramagnetic intermediates using electrochemistry and ESR. ${ }^{22-30}$ The ESR spin probe method $^{31}$ and a combination of AFM and ESR methods allow the closer study of surfactant surface aggregates. ${ }^{32}$ Direct use of ESR to study surfactant self-organization on the conductive surface is not possible, but the results of its application on non-conducting surfaces using AFM help answer difficult questions regarding surface micelle formation.

An urgent task is to replace platinum with palladium - the cheaper analogue from the viewpoint of catalytic and nanoelectronic applications. This paper discusses the results of the synthesis of nanolattices from this other noble metal, palladium, on the atomically smooth surface of pyrolytic graphite.

\section{Experimental}

\section{Reagents and materials}

We used palladium(II) chloride purchased from Sigma-Aldrich. Cetyltrimethylammonium bromide (CTAB) was purchased from Sigma-Aldrich and crystallized twice from hot acetone. Hydrazine hydrate was purchased from Sigma-Aldrich and used without additional purification. Highly ordered pyrolytic graphite (HOPG, Veeco Instruments Inc., USA) was used in all measurements as a solid support. HOPG was dried out before each experiment at $40{ }^{\circ} \mathrm{C}$ for two hours. The experiments have shown that this preliminary preparation stage plays an important role.

\section{Preparation of solutions for surfactant self-assembly study}

All solutions, which were studied in a fluid cell, were kept at room temperature before utilization. Using a special syringe, $2 \mathrm{ml}$ of original solution was introduced into the AFM fluid cell. After the experiment, the cell was washed with distilled water and acetone to remove any residue of the solution.

\section{Preparation and reduction of Pd salts}

Metal nanostructures on the solid support were synthesized in two stages. The synthesis includes the formation of surfactant self-assemblies at the solid support/surfactant solution interface, and subsequent reduction of the metal salt. In order to create surface micelles at the interface, droplets of $1 \mathrm{mM} \mathrm{CTAB}$ and $0.1 \mathrm{mM} \mathrm{PdCl}{ }_{2}$ water solutions were deposited on the clear support surface and were maintained at a certain temperature for 30 minutes. For complete metal reduction, $\mathrm{s}$ tenfold amount of hydrazine hydrate $\left(\mathrm{N}_{2} \mathrm{H}_{4} \cdot \mathrm{H}_{2} \mathrm{O}\right)$ was introduced to the solution. To remove the CTAB layer after complete solvent evaporation, the surface of the template was washed with ethanol and deionized water. Then the support with the metal particle layer was dried at $80^{\circ} \mathrm{C}$ for $2 \mathrm{~h}$. As mentioned above, the concentration of the amphiphilic compound should be 10 times greater than the concentration of palladium chloride. The concentration of palladium chloride was selected on the basis of the desired density of metal deposition.

\section{Control and measurement of temperature in the fluid cell}

The temperature of the cell was controlled using a Peltier element placed under the support with the investigated sample. Additionally, the temperature was measured using a small thermocouple inserted directly into the cell via a special channel. The temperature was registered with the help of a Digi-Sense Thermocouple Thermometer. The sample was stored under fixed conditions until the solution temperature equalled the support temperature.

\section{Atomic force microscopy investigation (AFM)}

Microimages of the support/liquid interface were obtained using a scanning probe microscope MultiMode V (Veeco, USA). Rectangular cantilevers RTESP (Veeco, USA) with silicone probes were used for measurements in the fluid cell (model MMTMEC). The investigated solution was introduced into the fluid cell (MMTMEC model). Before each experiment the fluid cell was cleaned with acetone and then with distilled water. Images were captured under the following conditions: integral gain - 0.5-1, proportional gain - 5-10, scan rate - 1-2 Hz. Distances in lateral and vertical dimensions were calibrated using an imaging special calibration grid (STR3-1800P, VLSI Standards Inc.) in the temperature range $20-60{ }^{\circ} \mathrm{C}$. The nonlinearity of the piezo-drive was not observed in this range. The images were captured using contact AFM mode. To cause minimum harm to the adsorbed film, as low as possible pressure force of the probe was set. Surface micelles at the graphite/liquid interface were examined using contact AFM mode in the fluid cell, while the synthesized palladium strips were examined in discontinuous contact mode in air.

\section{Transmission electron microscopy and energy dispersive X-ray (TEM-EDX) analysis}

The morphology and elemental composition of individual Pd particles were investigated using a Hitachi HT7700 TEM equipped with an EDX detector. The images were acquired at an accelerating voltage of $100 \mathrm{kV}$ and with a low beam current to minimize beam damage. The counting time for X-ray spectra was 20 seconds.

\section{X-ray fluorescence analysis}

Spectra were obtained with the help of an energy-dispersive $\mathrm{X}$-ray spectrometer EDX 800HS2 (Shimadzu). The device was equipped with a low power $(50 \mathrm{~W})$ transmission type X-ray tube (beam diameter $10 \mathrm{~mm}$ ). The operating voltage was $50 \mathrm{kV}$, the current was $625 \mu \mathrm{A}$ and the exposure time was $150 \mathrm{~s}$. 
Procedure for preparing and testing the membrane electrode assembly (MEA)

Production of the MEA with a palladium catalyst was carried out in two stages. The first includes the production of Pd strips deposited using the technique described in the previous sections. But in this case a carbon paper (gas diffusion layer Sigracet 25CC) with a size of $10 \times 10 \mathrm{~mm}^{2}$ was used as a support. Then, two gas diffusion layers with palladium were pressed onto both sides of the membrane (Nafion 115, thickness $-125 \mu \mathrm{m})$ at $150{ }^{\circ} \mathrm{C}$ under a pressure of $100 \mathrm{~kg} \mathrm{~cm}{ }^{-2}$.

The $1 \mathrm{~cm}^{2}$ MEA was placed in the body of a commercial fuel cell and studied on a test station with an electrochemical unit ECL 450 (ElectroChem Inc.) and gas-distributive unit HAS (ElectroChem Inc.). The flow rate of both hydrogen and oxygen was $20 \mathrm{ml} \mathrm{min}^{-1}$.

\section{Wetting angle}

The wetting angle was measured using a sessile drop method with a KRUSS DSA30. A wetting angle less than 90 degrees is typical for a hydrophilic surface, while an angle above 90 degrees is typical for a hydrophobic surface.

\section{Results and discussion}

\section{Surfactant self-assemblies}

Chemical deposition of metallic palladium on pyrographite was performed in accordance with the aforementioned method. To obtain a metal nanolattice, it is necessary to create conditions suitable for the formation of surfactant surface admicelles on the substrate. The AFM image of the adsorbed structure of $1 \mathrm{mM} \mathrm{CTAB}$ aqueous solution at the graphite/solution interface formed at $25^{\circ} \mathrm{C}$ is shown in Fig. 1A. A profile of the cross section of the image along the black line is shown in Fig. 1B. It represents a topographic modulation $d Z_{\mathrm{m}}$ in the position of the probe tip in the vertical direction.

It has been recently confirmed $^{34}$ that the structure adsorbed by the support surface represents the hemi-cylindrical admicelles shown in Fig. 2. Hemi-cylinders stick to the surface of a hydrophobic substrate by means of the hydro-
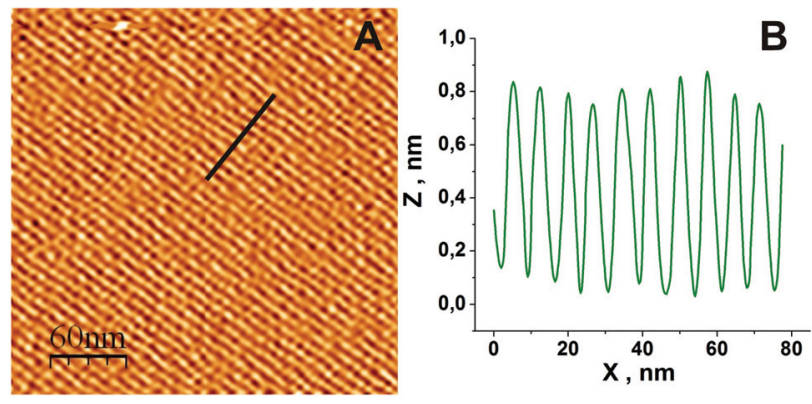

Fig. 1 AFM image of the adsorbed structure of $1 \mathrm{mM} C T A B$ aqueous solution at the graphite/solution interface at $25^{\circ} \mathrm{C}(\mathrm{A})$ and the topographic modulation in the position of the probe tip in the vertical direction along the black line (B).

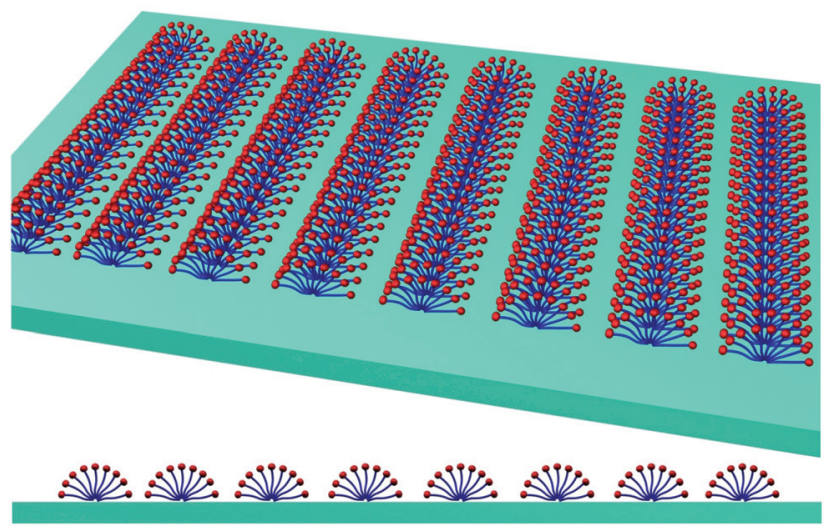

Fig. 2 Overall view of adsorbed CTAB micelles at the graphite/solution interface.

phobic tails of surfactant molecules in the near-contact zone. The diameter of the hemi-cylinders is approximately twice the length of CTAB molecules. The length of $\mathrm{CTAB}$ molecules is $4.54 \mathrm{~nm}$ at $25^{\circ} \mathrm{C} .{ }^{34}$

Fig. 3 shows the topographic modulation $d Z_{\mathrm{m}}$ obtained during scanning of the graphite/solution interface with hemicylindrical micelles of radius $r_{\mathrm{m}}$ using an AFM tip of radius $r_{\mathrm{t}}$. The adsorbed structure shown in Fig. 1A represents strips with repeat period $P_{\mathrm{m}}$ (Fig. 3) equal to $7.5 \mathrm{~nm}$. The modulation $d Z_{\mathrm{m}}$ depends on the period $P_{\mathrm{m}}$, and on the curvature radius of the probe $r_{\mathrm{t}}$.

The first direct image of the morphology of CTAB aggregates adsorbed from the aqueous solution on the hydrophobic substrate have been recently obtained using an AFM method. ${ }^{33}$ The aggregates exist in the form of "hemi-cylindrical halfmicelles", epitaxially oriented along the symmetry axes of the graphite surface. The distance between half-micelles is twice the length of the surfactant molecules. Such aggregates were observed in the concentration range $0.9-5.5$ of the critical micelle concentration (CMC). According to modern concepts, at a surfactant concentration below the volume of CMC, amphiphilic molecules are adsorbed substantially, orienting parallel to the surface according to a "head-to-head"/"tail-to-tail"

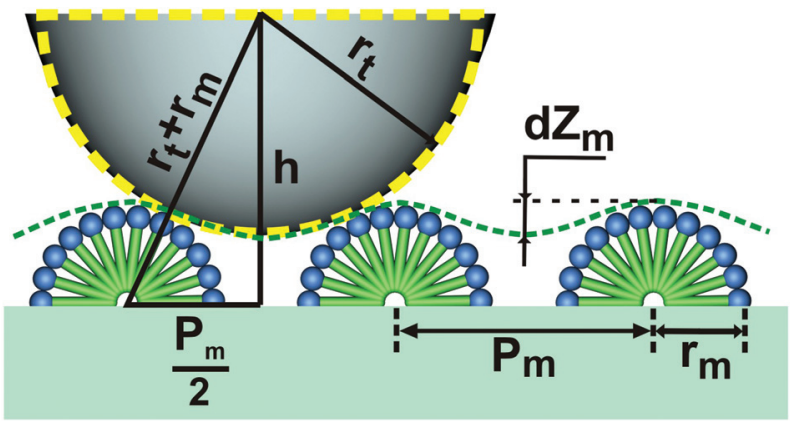

Fig. 3 Image of the topographic modulation $d Z_{m}$ obtained as a result of scanning the graphite/solution interface created by hemi-cylindrical micelles of radius $r_{m}$ using a hemisphere-like AFM probe of radius $r_{\mathrm{t}}$. 
scheme. At higher concentrations (>CMC), semi-cylinders arrange at the phase interface, forming periodic extended structures (strips), separated by a distance approximately equal to twice the length of the surfactant molecules. This structuring of surfactant molecules on the graphite substrates was observed for both types of surfactant - ionic and non-ionic. A key role in controlling the morphology of the aggregates is played by the crystal lattice structure of graphite, which orients the surfactant molecules along the graphite crystallographic directions. The determining criterion in this case was supposed to be the correspondence between the graphite lattice period $(0.246 \mathrm{~nm})$ and the length of the methylene link $(0.254 \mathrm{~nm})$. An increase in the packing density of hemicylinders with an increase in surfactant concentration has also been confirmed. ${ }^{16}$ So the amplitude of the topographic modulation depends on the surfactant concentration of hemicylindrical CTAB micelles at the phase interface of graphite/ solution; $d Z_{\mathrm{m}}$ decreases from $0.7 \mathrm{~nm}$ at $C=0.5$ CMC to $0.4 \mathrm{~nm}$ at $C=10 \mathrm{CMC}$.

A dependence of the same nature for the surfactant aggregates' period at the graphite/solution interface on the concentration of sodium dodecyl sulfate (SDS) has also been observed previously. ${ }^{35}$ The adsorbate period decreased from 7 to $5.2 \mathrm{~nm}$ with the increase in SDS concentration from 3 to $100 \mathrm{mM}$. It has been shown that an increase in concentration of $\mathrm{Mg}^{2+}$ ions leads to a denser packing of hemi-cylindrical micelles ${ }^{36}$ due to neutralization of the electrostatic repulsion between SDS head groups.

The temperature dependence of the repeat period has a critical nature: in the narrow temperature range of $1-1.5{ }^{\circ} \mathrm{C}$, a steep 2 -fold increase in the period is observed. ${ }^{16}$ Analysis of the interactions contributing to the temperature-induced structural changes gave the basis for introducing a new concept of a transition of the half-cylinders to pre-cylinders with a quantitative ratio of $2: 1$.

In ref. 32, similar hemi-cylindrical micelles from CTAB molecules have already been observed at the glass/solution phase interface; in a narrow temperature range of $28-28.6{ }^{\circ} \mathrm{C}$, an approximate doubling of the repeat period of the strips (from 5 to $11 \mathrm{~nm}$ ) was observed, i.e., hemi-cylindrical admicelles have been changed to cylindrical ones. It should be noted that the graphite surface is hydrophobic and the glass surface is hydrophilic (Table 1). In the case of the glass

Table 1 Values of the static contact angle measured using a sessile drop method, work of adhesion and hydrophilic/hydrophobic properties of the surfaces of HOPG and glass

\begin{tabular}{lllllll}
\hline No & Substrate & $\begin{array}{l}\mathrm{CA}(\mathrm{M}) \\
{\left[^{\circ}\right]}\end{array}$ & $\begin{array}{l}\mathrm{CA}(\mathrm{L}) \\
{\left[{ }^{\circ}\right]}\end{array}$ & $\begin{array}{l}\mathrm{CA}(\mathrm{R}) \\
{\left[{ }^{\circ}\right]}\end{array}$ & $\begin{array}{l}\text { WoA } \\
{\left[\mathrm{mN} \mathrm{cm}^{-1}\right]}\end{array}$ & $\begin{array}{l}\text { Hydrophilic }(90-) \\
\text { or hydrophobic } \\
(90+)\end{array}$ \\
\hline 1 & HOPG & 96.05 & 96.47 & 95.62 & 65.87 & HPB \\
2 & Glass & 45.31 & 46.98 & 43.65 & 122.78 & HPL
\end{tabular}

$\mathrm{CA}(\mathrm{M})$ is average contact angle, $\mathrm{CA}(\mathrm{L})$ and $\mathrm{CA}(\mathrm{R})$ are left and right contact angles, respectively, WoA is work of adhesion. substrate, there are also no specific crystallographic axes with a distance between them that could be comparable to the length of the methylene link. However, it should be noted that the value of the glass surface dispersity is $5 \mathrm{~nm}$ (ref. 32) approximately twice the length of the methylene link.

\section{Measurement of the curvature radius of the probe tip}

The radius of the probe tip can be estimated by measuring the topographic modulation during scanning of the micelles. According to Fig. 3, the following equations are valid:

$$
\begin{gathered}
h=r_{\mathrm{t}}+r_{\mathrm{m}}-d Z_{\mathrm{m}}, \\
\left(r_{\mathrm{t}}+r_{\mathrm{m}}\right)^{2}=h^{2}+\left(P_{\mathrm{m}} / 2\right)^{2} .
\end{gathered}
$$

A solution of the system of eqn (1 and 2) in relation to $r_{\mathrm{t}}$ is

$$
r_{\mathrm{t}}=d Z_{\mathrm{m}} / 2+P_{\mathrm{m}}^{2} / 8 d Z_{\mathrm{m}}-r_{\mathrm{m}} .
$$

By substituting $d Z_{\mathrm{m}} \sim 0.7 \mathrm{~nm}$ and $P_{\mathrm{m}} \sim 7.5 \mathrm{~nm}$ from Fig. 3, a value for the curvature radius of the probe tip $r_{\mathrm{t}} \sim 10 \mathrm{~nm}$ was obtained. This corresponds to a value of 10-13 $\mathrm{nm}$ declared by the manufacturer.

\section{Palladium nanolattice on HOPG}

Fig. 4A shows the AFM contact mode image of the Pd selfassemblies on the surface of atomically smooth HOPG obtained using chemical deposition in a liquid medium at $25{ }^{\circ} \mathrm{C}$ with the aid of a surface micellar template. The template was formed by CTAB aggregates and later rinsed off after the synthesis was complete. Fig. 4 shows parallel matrices of linear chains of $\mathrm{Pd}$ nanoparticles with a sufficiently long length (several tens of microns) compared with the width $(\sim 40 \mathrm{~nm})$. It should be noted that the nanoparticles are randomly arranged on part (nearly $30 \%$ ) of the surface of the same sample, predominantly at the edge of the Pd substrate (ESI $\dagger$ ). Perhaps this is due to the inhomogeneity of the surface properties of the substrate at the edges and near the center.

The cross-sectional shape and arrangement of the palladium strips are very different from those of the platinum strips. $^{16}$ Palladium spreads better over the hydrophobic surface of HOPG and has a contact angle less than an order of
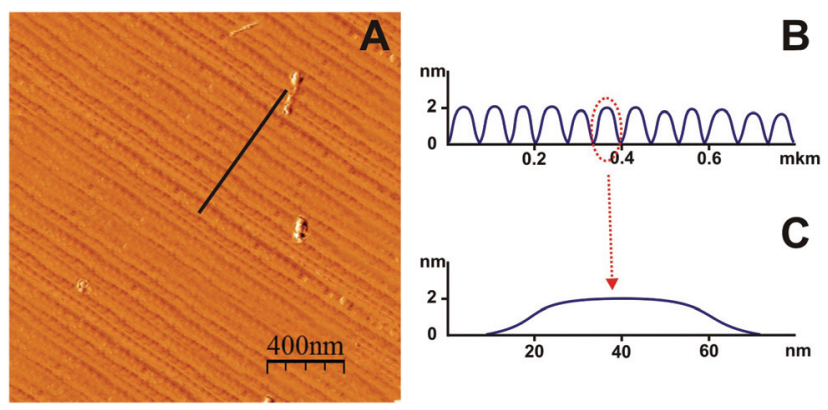

Fig. 4 AFM contact mode image of the Pd self-assemblies on the surface of atomically smooth HOPG at $25^{\circ} \mathrm{C}$ (A), topographic modulation of the probe tip position in the vertical direction along the black line (B), and profile of one of the strips (C). 
magnitude than platinum has in the same conditions. The palladium strips lie close to each other and are almost in contact, while the distance between the platinum strips is nearly $100 \mathrm{~nm}$. Despite these inherent differences, it is necessary to emphasize the universality of the developed method to obtain one-dimensional nanostructures of precious metals on a solid surface.

For the synthesis of parallel Pd strips on a graphite surface, a drop of $1 \mathrm{mM} \mathrm{CTAB}$ solution and $0.1 \mathrm{mM} \mathrm{PdCl}_{2}$ solution in water was applied to the clean surface of HOPG in the liquid cell.

Surface admicelles were formed over the next 30 minutes. Then, $\mathrm{Pd}^{2+}$ ions were reduced with $5 \mathrm{mM}$ hydrazine solution over $1 \mathrm{~h}$. Then, surface micelles were removed from the surface by washing with water and ethanol and the fluid cell was dried at $40^{\circ} \mathrm{C}$ for $4 \mathrm{~h}$.

The elemental composition of the material deposited on the surface of HOPG was analyzed using X-ray fluorescence spectroscopy. According to the characteristic lines at $21.12(\mathrm{~K} \alpha)$ and $23.80(\mathrm{~K} \beta) \mathrm{keV}$ in Fig. 5, it can be concluded that the material contains Pd particles. There were no characteristic lines of bromine at $11.91 \mathrm{keV}(\mathrm{K} \alpha)$ and $13.29 \mathrm{keV}(\mathrm{K} \beta)$ indicating the absence of CTAB molecules containing $\mathrm{Br}$ ions.

To investigate Pd using TEM, the metal was deposited on the surface of copper grids ( $300 \mathrm{mesh}$ ) covered with a formvar membrane. The deposition occurred using the method mentioned above. During the deposition of Pd on formvar, separate metal particles were obtained instead of an arranged system of metal strips. The sizes of the particles are $2-5 \mathrm{~nm}$ (Fig. 6). The properties of the formvar surface significantly differ from the properties of the HOPG surface. This fact did not allow arranged metal strips to be formed. However, the elemental composition of the deposited material was confirmed. In Fig. 7 the EDX spectrum relating to the TEM image area (Fig. 6) is shown. Two lines of $\mathrm{Pd}\left(M_{\zeta}=0.286 \mathrm{kV}, M_{\gamma}=\right.$ $0.532 \mathrm{kV}$ ) are clearly seen in the spectrum. Lines of carbon, silica and copper are also seen in the spectrum. These lines correspond to the substrate. ${ }^{37}$ In addition, the lack of bromine lines in the spectrum confirms that other components of the reaction are not included in the obtained product.

The diagnostic curves of MEA with a surface density of Pd of $0.5 \mathrm{mg} \mathrm{cm}{ }^{-2}$ on both the anode and cathode sides

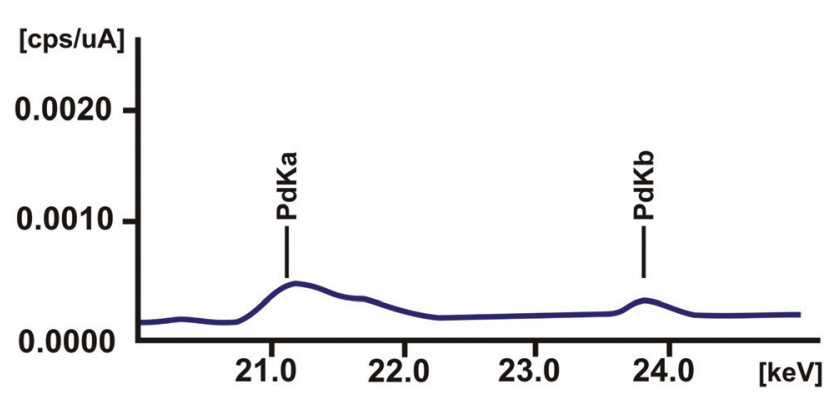

Fig. 5 X-ray fluorescence spectrum of the substrate surface with the deposited material at $25^{\circ} \mathrm{C}$.

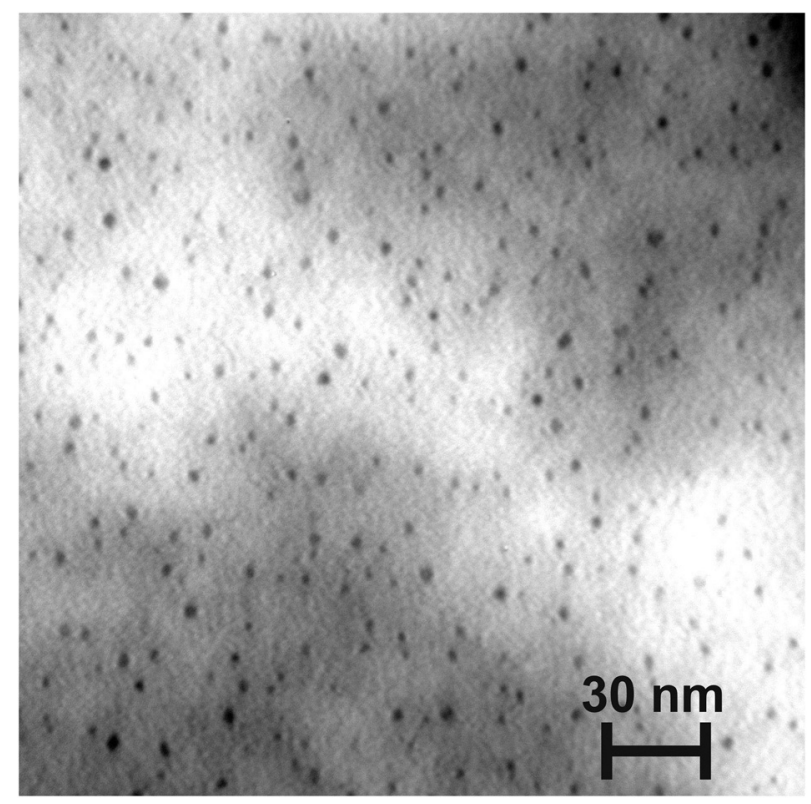

Fig. 6 TEM image of Pd particles deposited on the surface of formvar using CTAB micellar template.

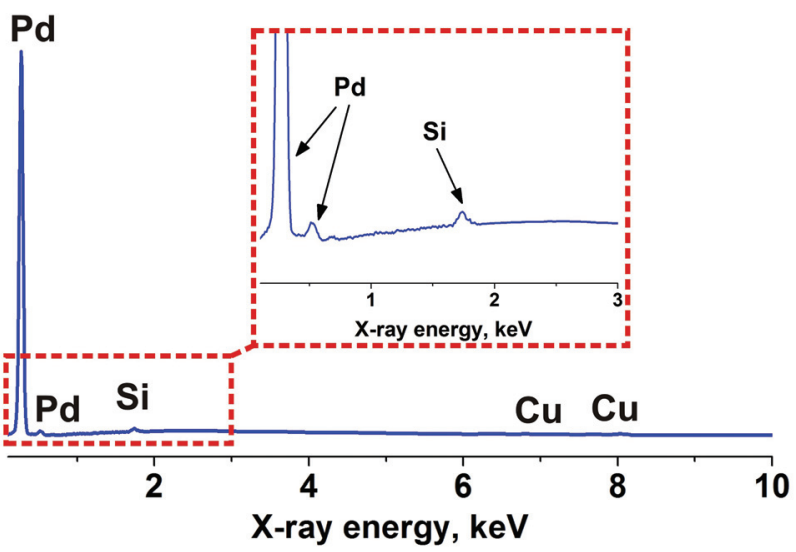

Fig. 7 Spectrum of TEM-EDX analysis of Pd particles deposited on the surface of formvar using CTAB micellar template.

in an $\mathrm{H}_{2} / \mathrm{O}_{2}$ fuel cell are shown in Fig. 8. The curve of the dependence of the power density on the current density shows that a maximum power density of $2.4 \mathrm{~mW} \mathrm{~cm}{ }^{-2}$ is achieved at a current density of $11 \mathrm{~mA} \mathrm{~cm}{ }^{2}$. These data confirm that the precipitated strips are composed of metallic palladium.

The template directed sintering process of Pd nanoparticles mediated by surface micelles (Fig. 9A) could be divided into several stages. During chemical reduction, individual Pd nanoparticles are formed through nucleation along the long axis of the surface micelles (Fig. 9B) and then linked together into linear chains oriented in the same direction, as schematically shown in Fig. 9C. Particle growth will occur between the admicelles. After washing off the template from the surface 


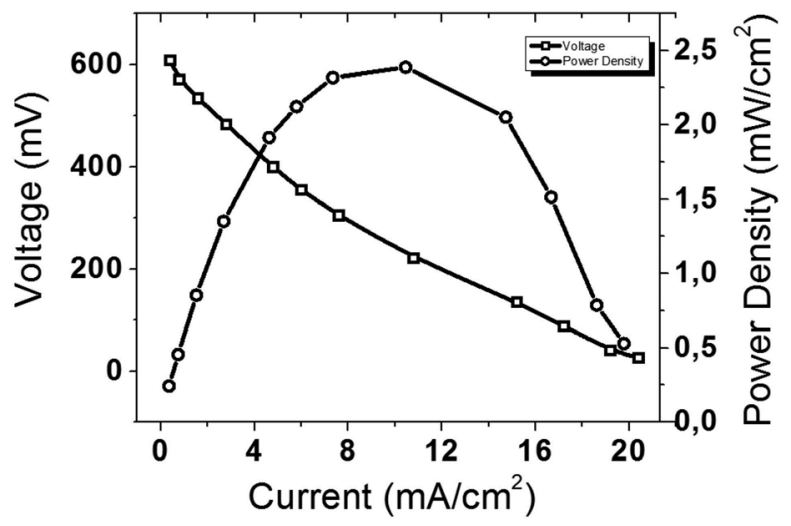

Fig. 8 Diagnostic curves of the MEA with a surface density of Pd of $0.5 \mathrm{mg} \mathrm{cm}^{-2}$ in an $\mathrm{H}_{2} / \mathrm{O}_{2}$ fuel cell.
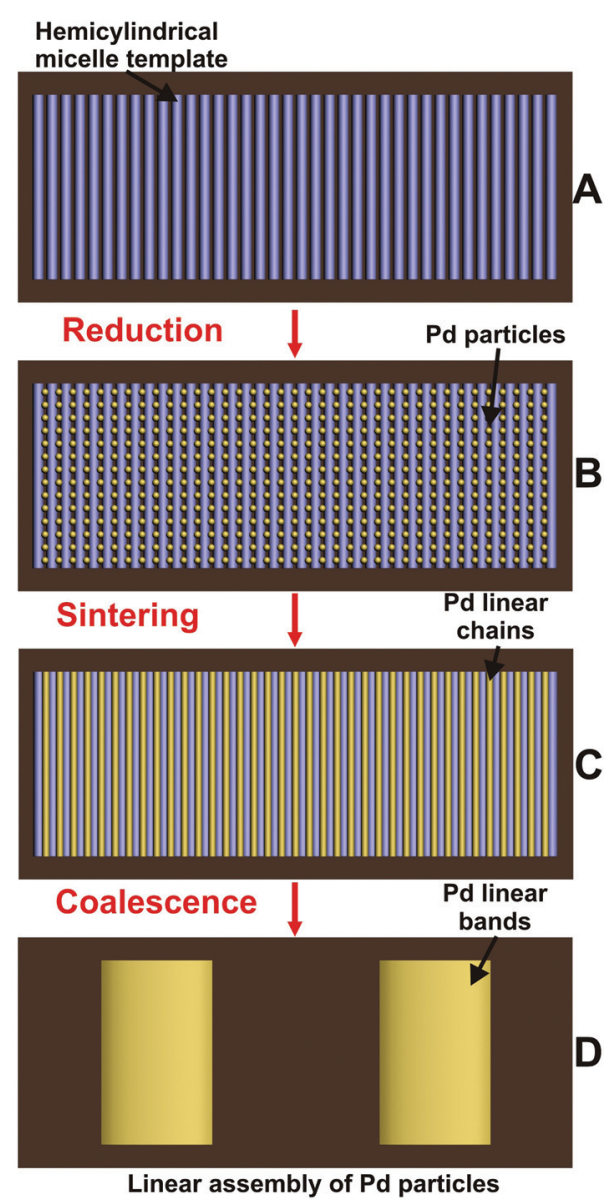

Fig. 9 Illustration of the mechanism of formation of Pd strips using a micellar template.

micelles, coalescence of several (about 9 in this case) neighboring Pd linear chains into a broader strip of Pd (Fig. 9D) was observed. The height of the strips is $2 \mathrm{~nm}$, the width is $40 \mathrm{~nm}$ and the repeat period is $67 \mathrm{~nm}$ (according to Fig. 4).

\section{Conclusions}

The method ${ }^{16,32}$ of synthesis of linear nanoclusters of noble metals on a solid support was expanded to produce a palladium lattice. The morphological characteristics of the linear clusters (the repeat period of the Pd strips is $65 \mathrm{~nm}$, width $40 \mathrm{~nm}$ and height $2 \mathrm{~nm}$ ) are attractive for nanotechnology applications. The elemental composition of the metal clusters was confirmed using X-ray fluorescence and TEM-EDX methods. The fact that the strips are composed of metallic Pd was also confirmed by testing the membrane electrode assembly with the strips in a commercial fuel cell. The work is attractive because it describes a quick and cheap method for the synthesis of a nanoscale Pd lattice on a solid support.

\section{Acknowledgements}

Financial support from the Russian Foundation for Basic Research (grant no. 14-03-00258A) is greatly appreciated.

\section{References}

1 G. Kartopu and O. Yalçın, Electrodeposited Nanowires Their Appl., 2010, 228, 113-140.

2 T. Ahmadi, Z. Wang, T. Green, A. Henglein and M. El-Sayed, Science, 1996, 272, 1924-1925.

3 T. Ahmadi, Z. Wang, A. Henglein and M. El-Sayed, Chem. Mater., 1996, 8, 1161-1163.

4 N. Melosh, A. Boukai, F. Diana, B. Gerardot, A. Badolato, P. Petroff and J. Heath, Science, 2003, 300, 112-115.

5 Y.-J. Han, J. Kim and G. Stucky, Chem. Mater., 2000, 12, 2068-2069.

6 J. Shui and J. Li, Nano Lett., 2009, 9, 1307-1314.

7 M. Shirai, K. Igeta and M. Arai, Chem. Commun., 2000, 623624.

8 D. Lee, J. Choung, Y. Pyun, K. Son and W. Park, 3rd International Nanoelectronics Conference. Book of Abstracts, 2010, pp. 1282-1283.

9 W. Wu and L. Wang, Nano Lett., 2011, 11, 2779-2785.

10 G. Kartopu, S. Habouti and M. Es-Souni, Mater. Chem. Phys., 2008, 107, 226-230.

11 L. Piraux, S. Dubois, A. Fert and L. Belliard, Eur. Phys. J. B, 1998, 4, 413-420.

12 D. Strukov, D. Snider, D. Stewart and R. Williams, Nature, 2008, 453, 80-83.

13 L. Chua, IEEE Trans. Circuit Theory, 1971, 18, 507-519.

14 H. Kawasaki, M. Uota, T. Yoshimura, D. Fujikawa, G. Sakai, M. Annaka and T. Kijima, Langmuir, 2005, 21, 1146811473.

15 H. Kawasaki, M. Uota, T. Yoshimura, D. Fujikawa, G. Sakai and T. Kijima, Colloid Interface Sci., 2006, 300, 149-154.

16 M. Kadirov, I. Nizameev and L. Zakharova, J. Phys. Chem. C, 2012, 116, 11326-11335. 
17 M. Kadirov, A. Bosnjakovic and S. Schlick, J. Phys. Chem. B, 2005, 109, 7664-7670.

18 M. Danilczuk, A. Bosnjakovic, M. Kadirov and S. Schlick, J. Power Sources, 2007, 172, 78-82.

19 A. Bosnjakovic, M. Kadirov and S. Schlick, Res. Chem. Intermed., 2007, 33, 677-687.

20 T. Pashirova, E. Zhil'tsova, R. Kashapov, S. Lukashenko, A. Litvinov, M. Kadirov, L. Zakharova and A. Konovalov, Russ. Chem. Bull., 2011, 59, 1745-1752.

21 L. Zakharova, Y. Kudryashova, N. Selivanova, M. Voronin, A. Ibragimova, S. Solovieva, A. Gubaidullin, A. Litvinov, I. Nizameev, M. Kadirov, et al., J. Membr. Sci., 2010, 364, 90-101.

22 M. Kadirov, Yu. Budnikova, T. Gryaznova, O. Sinyashin, M. Bubnov, A. Krashilina and V. Cherkasov, Russ. Chem. Bull., 2007, 56, 104-107.

23 M. Kadirov, E. Tretyakov, Y. Budnikova, M. Valitov, K. Holin, T. Gryaznova, V. Ovcharenko and O. Sinyashin, J. Electroanal. Chem., 2008, 624, 69-72.

24 Y. Budnikova, T. Gryaznova, M. Kadirov, E. Tret'yakov, K. Kholin, V. Ovcharenko, R. Sagdeev and O. Sinyashin, Russ. J. Phys. Chem. A, 2009, 83, 1976-1980.

25 M. Kadirov, E. Tret'yakov, Y. Budnikova, K. Kholin, M. Valitov, V. Vavilova, V. Ovcharenko, R. Sagdeev and O. Sinyashin, Russ. J. Phys. Chem. A, 2009, 83, 21632169.
26 M. Kadirov, Y. Budnikova, K. Kholin, M. Valitov, S. Krasnov, T. Gryaznova and O. Sinyashin, Russ. Chem. Bull., 2010, 59, 466-468.

27 J. Ciszewski, D. Mikhaylov, K. Holin, M. Kadirov, Y. Budnikova, O. Sinyashin and D. Vicic, Inorg. Chem., 2011, 50, 8630-8635.

28 R. Galimullina, M. Valitov, Y. Spiridonova, E. Musina, S. Krasnov, M. Kadirov, A. Karasik, Y. Budnikova and O. Sinyashin, Russ. J. Phys. Chem. A, 2011, 85, 2214-2221.

29 M. Kadirov, K. Kholin, E. Tselishcheva, V. Burilov and A. Mustafina, Russ. Chem. Bull., 2013, 62, 1327-1331.

30 K. Kholin, M. Valitov, V. Burilov, E. Tselischeva, S. Strekalova, A. Mustafina, Yu. Budnikova and M. Kadirov, Electrochim. Acta, 2015, 182, 212-216.

31 Y. Wang, D. Lu, H. Yan and R. Thomas, J. Phys. Chem. B, 1997, 101, 3953-3956.

32 M. Kadirov, A. Litvinov, I. Nizameev and L. Zakharova, J. Phys. Chem. C, 2014, 118, 19785-19794.

33 L. Zook and J. Leddy, Anal. Chem., 1996, 68, 3793-3796.

34 S. Manne, J. Cleveland, H. Gaub, G. Stucky and P. Hansma, Langmuir, 1994, 10, 4409-4413.

35 E. Wanless and W. Ducker, J. Phys. Chem., 1996, 100, 32073214.

36 E. Wanless and W. Ducker, Langmuir, 1997, 13, 1463-1474.

37 J. V. Niemi and S. Saarikoski, Atmos. Chem. Phys. Discuss., 2006, 6, 6753-6799. 